\section{ARS Tech}

Copyright $(2020$ UMS Publisher

\section{Applied Research and \\ Smart Technology}

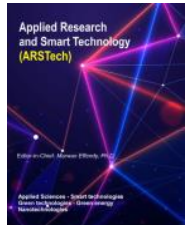

ISSN 2722-9645

Research Article

\title{
Performance prediction of trailing-edge cooling system of gas turbine blade using detached eddy simulation
}

\author{
Agus Jamaldi ${ }^{1, *}$, Hasan Khamis Hassan ${ }^{2}$ \\ ${ }^{1}$ Department of Mechanical Engineering, Sekolah Tinggi Teknologi Warga Surakarta \\ Jalan Raya Solo - Baki Km.2, Kwarasan, Solo Baru, Sukoharjo, 57552. Indonesia. \\ ${ }^{2}$ Zanzibar Water Authority, P. O. Box 460, Zanzibar, Tanzania. E-mail: hassan.hassan@zawa.go.tz \\ ${ }^{*}$ Corresponding author: agus.jamaldi@gmail.com
}

Permalink (DOI): $\underline{\text { https://doi.org/10.23917/arstech.v1i1.15 }}$

\begin{tabular}{|c|c|}
\hline ARTICLE INFO & ABSTRACT \\
\hline Article history: & This study evaluates the performance of the trailing-edge (TE) cooling system in \\
\hline Received 31 March 2020 & a gas turbine blade. Eddy Simulation (DES), based on the turbulence model of \\
\hline Revised 06 April 2020 & Spallart-Almaras (SA), was used to simulate the TE cooling system. A TE \\
\hline Accepted 31 Mav 2020 & configuration with a five-row staggered pin-fin arrangement was employed as a \\
\hline Available online 06 Iune 2020 & computational domain. Three parameters, i.e., the coefficient of heat transfer on \\
\hline Published reoularly 15 Julv 2020 & the pin-fins surface $\left(h_{\text {pin }}\right)$, the coefficient of discharge $\left(C_{\mathrm{D}}\right)$, and the effectiveness \\
\hline & $\begin{array}{l}\text { of adiabatic film cooling }\left(\eta_{\text {aw }}\right) \text { were used to assess the performances. The findings } \\
\text { denoted that the heat transfer fluctuations occurred on the surface of the pin-fins }\end{array}$ \\
\hline Keywords: & in each row. The discharge coefficient increased with the rising of the blowing \\
\hline Trailing-edge cooling & ratio. The trend predicted data of $\eta_{\text {aw }}$ were in good agreement with realistic \\
\hline Detached eddy simulation & discrepancies compared to other researches, mainly for higher blowing ratio. The \\
\hline Discharge coefficient & average effectiveness along the cut-off region was to be sensitive to the blowing \\
\hline Film cooling effectiveness & ratio changes, which was attributed to the structures of turbulent flow along the \\
\hline Staggered array & mixing region. \\
\hline
\end{tabular}

\section{INTRODUCTION}

A blade cooling system of the gas turbine is necessary to ensure the lifetime of a turbine blade. The important part of the turbine blade that needed more attention is trailing-edge because it operates in extreme conditions such as high temperature, limited material strength, and very high pressure [1][2]. These extreme conditions cause serious aerothermodynamic problems for engine parts such as liners, blades, and vanes, i.e., melting, oxidation, crack, thermal fatigue, and buckling [3][4][5]. To address these problems, a cooling system is needed. This system works by utilising the fluid flow that passes through the turbine blade. Other manners widely used are by adding pin-fin arrangements, an extension of lands [6][7]. The purpose of adding this pin-fin is to produce a turbulent 
flow of cooling gas, so the heat transfer that occurred is higher. Another advantage of adding a pin-fin is to strengthen the construction of the turbine blade [8]. The turbulent flow is generated from the flow that passed through the pin-fin arrangement provides a further effect behind the slot-exit, and on the adiabatic wall, the intensity of turbulent flow made different patterns resulted from mixing the mainstream and cooling gas so that this mixing could reduce the mainstream with a higher temperature. On the other hand, pin fins in various configurations have been applied in many applications [9], for example, in-line [10] and staggered array [11][12][13]. The most widely used pin-fin shapes were circles [14][15], ellipses [16][17], two rows long rib arrays [18][19].

The research of TE cooling systems has been carried out both experimentally and numerically. Martini et al. [2][20][21] had conduct experiments on cooling systems of gas turbine blades for many years. Wall heat transfer and pressure loss in a TE cooling passage were also numerically simulated by Effendy et al. [22]. Another research has been carried out by Horbach et al. [23], whereas an investigation related to TE cooling is influenced by differences geometry and edge thickness. The findings indicated that the edge thickness strongly influences the predicted data of the discharge coefficient and effectiveness. Another method used to determine turbulent flow from mixing mainstream and coolant gas behind the slot-exit was a Pressure Sensitive Paint technique (PSP) like an experiment conducted by Yang et al. [4]. The results revealed that this technique could well capture a mixture of the mainstream with the cooling flow and the distribution of adiabatic film cooling effectiveness.

Furthermore, many previous researchers' research of the TE cooling system-based on simulations approach has been carried out using different methods [24][25]. Several turbulence models were widely used in investigating the cooling performance on gas turbine blades, such as steady RANS, unsteady RANS, DES, and Large Eddy Simulation (LES) [26][27][28]. Also, Effendy et al. [29] studied about TE cooling system, which was influenced by the thickness ratio of edge $(t)$ to the height of the cooling slot $(H)$. The results of the research found that cooling effectiveness increased with a rising $t / H$ ratio. In contrast, Gao et al. [30] represented the study of DES turbulence model. It was found that the prediction of TE cooling by using DES gives better results as compared to the RANS method. In regards with the research conducted by Effendy, et al [29], the present research was to predict numerically a system of blade TE cooling in a gas turbine with DES based on the SA turbulence model. Three key parameters were investigated related to cooling performance of TE gas turbine i.e parameters, i.e., heat transfer on the pin-fins surface, $C_{\mathrm{D}}$, and $\eta_{\text {aw }}$. The research focuses on the relationship between TE cooling and internal cooling due to the blowing ratios.

\section{NUMERICAL SIMULATION}

\subsection{Computational domain}

The design, geometry, and meshing of specimens used in this study refer to Effendy's research [29]. Figure 1 provides the computational domain and flow boundary conditions. The cooling slot has a width of $12 \mathrm{~mm}$ with a pitch spacing $(S) 12 \mathrm{~mm}$, in the cooling channel ( $L_{1}$ zone). There are five pin-fins arrangement with a slope of $(\alpha) 10$ degrees. The pin-fins diameter $(D)$ and the cooling-slot height $(H)$ have the same dimensions, i.e., $4.8 \mathrm{~mm}$. Pinfins distance to spanwise $(S)$ direction is $2.5 D$, and streamwise $(S \mathrm{x})$ direction is $2.167 D$, thus formed equilateral triangles. The meshing of the test specimen is given in Figure 2.

\begin{tabular}{cccccccccc}
\hline Dimension & $L_{1}$ & $L_{2}$ & $L_{3}$ & $S$ & $S_{\mathrm{x}}$ & $t$ & $H$ & $D$ & $\alpha$ \\
\hline $\mathrm{mm}$ & 52 & 14.4 & 60 & 12 & 10.4 & 4.8 & 4.8 & 4.8 & $10^{\circ}$ \\
\hline
\end{tabular}

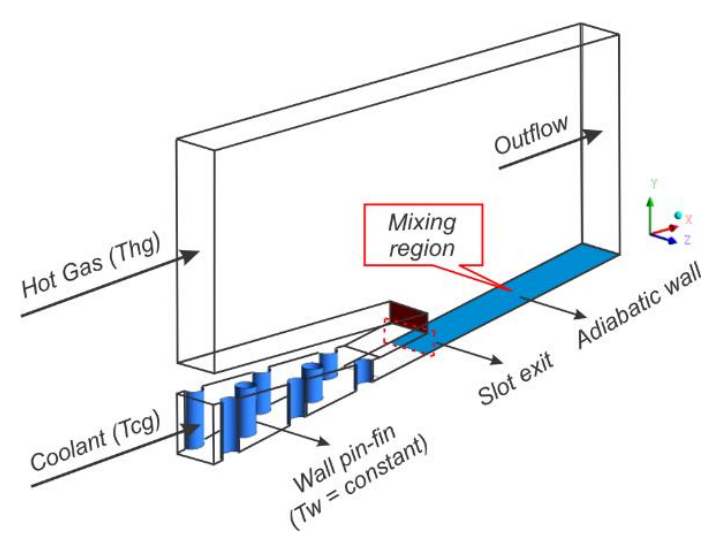

Figure 1. Computational domain.

\subsection{Initial flow and boundary condition}

In the study, both flow conditions and constraints adopted the same experimental setup as used in Martini's experiments, as shown in Table 1.

Table 1. Experimental setup.

\begin{tabular}{lll}
\hline \multicolumn{1}{c}{ Mainstream flow } & \multicolumn{1}{c}{ Coolant flow } \\
\hline$R_{\mathrm{hg}}=250,000$ & $T_{\mathrm{c}^{\prime}}, L_{2 \text { exit }}$ & $=295-330 \mathrm{~K}$ \\
$M \mathrm{a}_{\mathrm{hg}}=0,125$ & $T_{\mathrm{c}}, L_{1 \text { inlet }}$ & $=293 \mathrm{~K}$ \\
$\boldsymbol{u}_{\mathrm{hg}}=56 \mathrm{~m} / \mathrm{s}$ & $T_{\mathrm{u}_{\mathrm{c}}}$ & $=5 \%$ \\
$T_{\mathrm{u}}=7 \%$ & $M$ & $=0,2-1,25$ \\
$T_{\mathrm{hg}}=500 \mathrm{~K}$ & & \\
$P_{\mathrm{hg}}=105 \mathrm{kPa}$ & & \\
\hline
\end{tabular}




\subsection{Meshing and simulation}

In this simulation, the mesh was kept at a high standard of grids up to $\Delta y^{+}<1$ for all surfaces. It is an attempt to make sure an adequate high spatial resolution of the unsteadiness in the mixing region, mainly along the adiabatic wall's surface. It was built in more exceptional quality mesh up to $\Delta y^{+}<0.5$ on average, as previously studied by Effendy et al. [31]. The 3-D domain spacing accuracy must be smooth enough to address the DES method to the blending factor $(\mathrm{F})$ requirement.

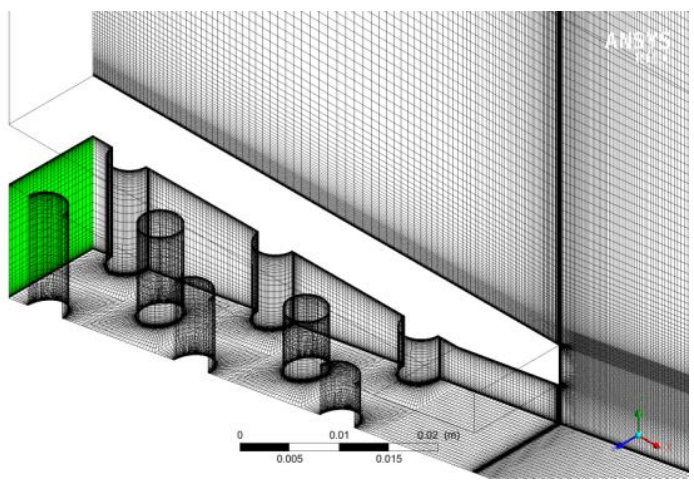

(a)

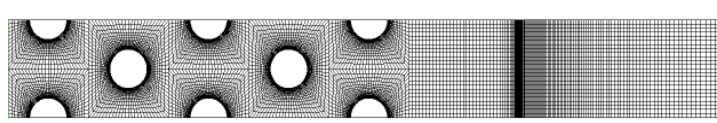

(b)

Figure 2. Mesh. (a) 3D view. (b) Bottom view.

The finite-volume approach was used to resolve the governance equations of incompressible flow. Equations were spatially resolved by second-order precision on multi-block organised grids, while provisional computed using the $2^{\text {nd }}$ order scheme was entirely implicit manner. The algorithm of SIMPLEC was employed by the $2^{\text {nd }}$ order simulation scheme utilised to all equations of flow fields such as energy, momentum, and pressure of the non-steady RANS and DES calculations.

\subsection{Film-cooling effectiveness}

The film-cooling efficiency was calculated by formulation (1);

$\eta_{a w}=\frac{T_{h g}-T_{a w}}{T_{h g}-T_{c}}$

$T_{\mathrm{hg}}$ is the temperature of hot gas at the main flow, $T_{\mathrm{aw}}$ is the temperature of adiabatic wall surfaces, and $T_{\mathrm{c}^{\prime}}$ is the coolant gas's temperature among two adjacent pin-fin arrays that measured in the centrum of the coolant slotexit.

The coefficient of discharge, $C_{\mathrm{D}}$, was formulated as follow

$$
\begin{aligned}
& C_{D}=\frac{\dot{m}_{c, \text { real }}}{\dot{m}_{c, \text { ideal }}}, \\
& C_{D}=\frac{\dot{m}_{c, \text { real }}}{p_{1, t} \cdot\left(\frac{p_{2}}{p_{1, t}}\right)^{\frac{\kappa+1}{2 \kappa}} \cdot A_{\text {slot }} \cdot \sqrt{\frac{2 \kappa}{(\kappa-1) \cdot R \cdot T_{1, t}}\left[\left(\frac{p_{1, t}}{p_{2}}\right)^{\frac{\kappa-1}{\kappa}}-1\right]}}
\end{aligned}
$$

where $T_{1, t}$ and $p_{1, t}$ is total temperature and pressure at the coolant inflow, respectively, $\mathrm{p}_{2}$ is static pressure at the coolant slot-exit, $\mathrm{A}_{\text {slot }}$ is the cross-section area of coolant slot- exit, $\kappa$ is the capacity of specific heat and $R$ is the constant of gas.

\section{RESULTS AND DISCUSSION}

Numerical simulation of the gas turbine's blade TE cooling system has been carried out by implementing the DES-SA turbulence model. It successfully identified three main parameters, i.e., the heat transfer on the pin-fins surface $\left(h_{\text {pin }}\right)$, the coefficient of discharge, and the effectiveness of adiabatic film cooling. The results describe as follows.

\subsection{Heat transfer coefficient}

Figure 3 provides the heat-transfer (HTC) coefficient at the superficies of the pin-fin arrays on the various blowing ratios at the coolant slot-exit, called as throat section. It was found that the trends of the heat transfer have similarities in three blowing ratios. Effendy et al. [32] found that the average coefficient of heat transfer at the surface pin-fin within the cooling passage is marginally increased. The heat-transfer coefficient is decreased after the fourth row of the pin-fin array. The highest $h_{\text {pin }}$ occurred on the fourth pin.

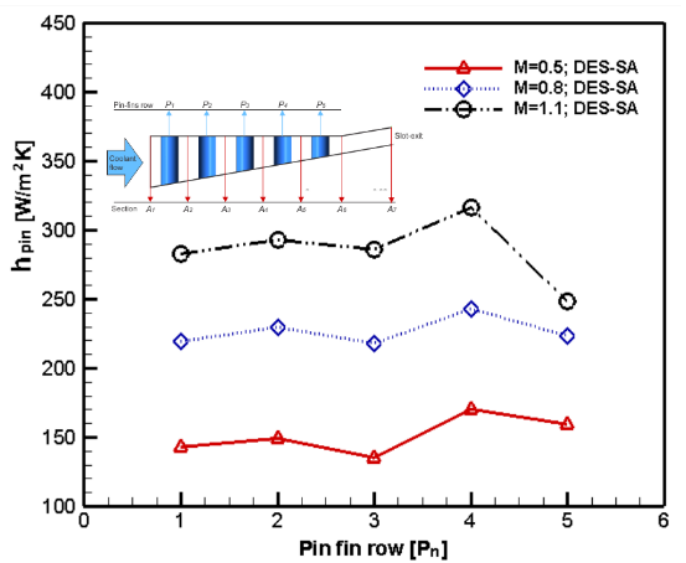

Figure 3. Pin-fin HTC.

Due to the turbulent flow effect of cooling gas that passed through the fin-pin arrangement, it caused different heat transfer on each pin. Effendy et al. [33] highlighted 
the combined impact of the pin-fin array and the converging passage influences the motion of the coolant air through the pin-fin, which affects the near-wall turbulent flow structures and their growth.

\subsection{Discharge coefficient}

The $\mathrm{C}_{\mathrm{D}}$ reflects the discharge action of the trailing blade of the cooling opening. This formula exposes the real flow of coolant mass against the magnificent mass-flux due to isentropic development from the upstream area to the free-flow at the ejection in the slot-exit.

Figure 4 indicates the discharge coefficient $\left(\mathrm{C}_{\mathrm{D}}\right)$ of the research results. The results are consistent with previous research conducted by Martini et al. [2][18], Horbach et al. [20], and Effendy et al. [26]. Hence, the current study is slightly under predictions compared to the others. It can be explained that the $\mathrm{C}_{\mathrm{D}}$ value increases with a rising blowing ratio $(\mathrm{M})$. It is due to ribs or pin-fins arrangement in the $\mathrm{L} 1$ zone, which causes the difference of main flow velocity distribution, which entered the $\mathrm{L}_{3}$ section. The increase in the blowing ratio matches the changes of the real coolant mass flow inside the cooling slot.

This finding confirms the correct discovery of filmcooling effectiveness, which, as discussed above, also results in sound harmony. Therefore, three validation studies using the baseline are necessary for further research to be established.

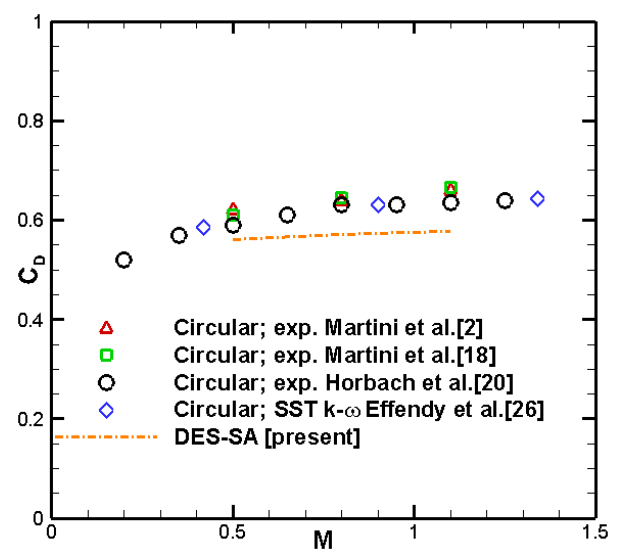

Figure 4. Discharge coefficient.

\subsection{Film cooling effectiveness}

The effectiveness of film cooling $\left(\eta_{\text {aw }}\right)$ is an important parameter that needed to be analysed on the TE cutback section. It can be obtained by calculating the average value of $\eta_{\text {aw }}$ on the adiabatic/protected wall surface.

Figure 5(a), (b) and (c) indicate film cooling effectiveness $\left(\eta_{\text {aw }}\right)$ that occurred at the adiabatic wall in three different blowing ratios $(\mathrm{M})$ with non-dimensional length $(x / H)$ ( $x$ denotes the length of $\mathrm{L}_{3}$ zone, and $\mathrm{H}$ denotes the high of slot exit). Figure 5(a) presents the simulation results of $\eta_{\text {aw }}$ at $M=0.5$. The results agree well with measurements data carried out by Martini et al. [2] [18] and Effendy et al. [26], while the difference in simulation results with the other research was $4.7 \%$. The result indicates that the mixture of hot and cold gas behind slot-exit made the significant cooling on an adiabatic wall surface.

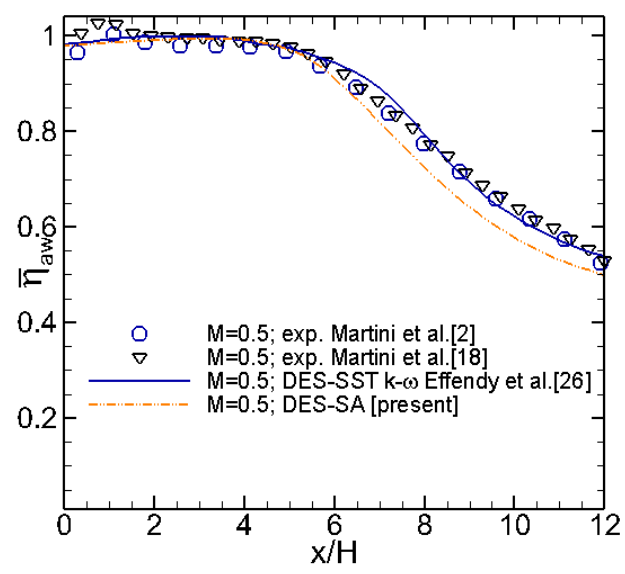

(a) $\mathrm{M}=0.5$

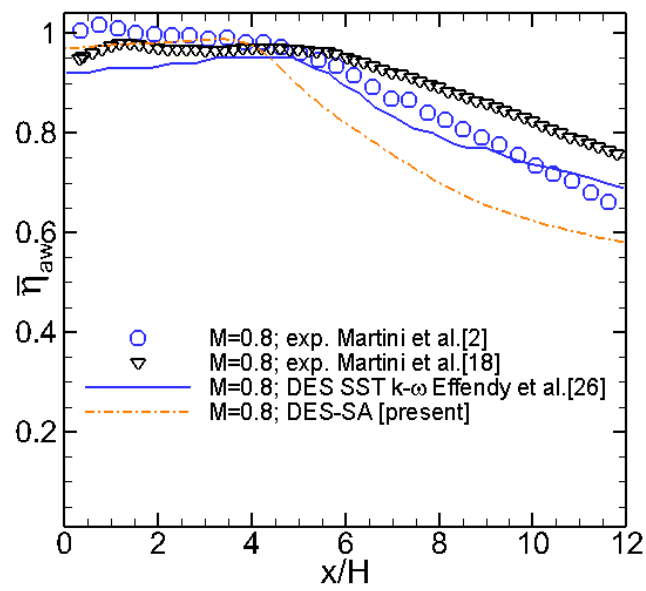

(b) $\mathrm{M}=0.8$

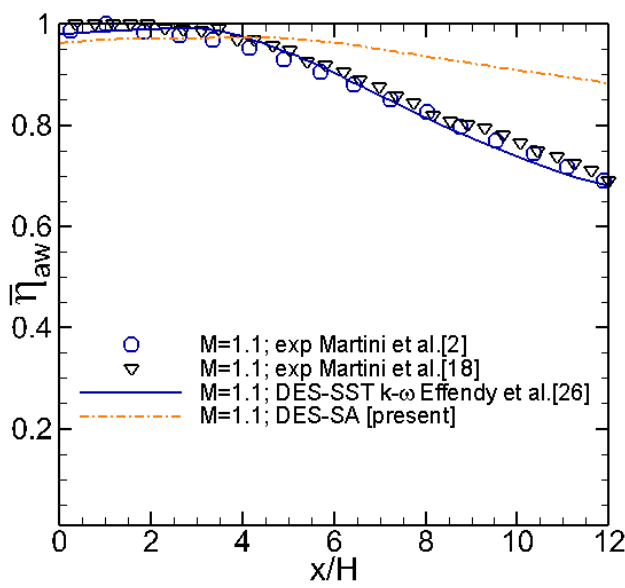

(c) $M=1.1$

Figure 5. Film cooling effectiveness. 
Figure 5 (b) shows the $\eta_{\text {aw }}$ at $M=0.8$, whereas there is an "under-prediction" at position $\mathrm{x} / \mathrm{H}>4$. It is attributed to hot gas dominated the temperature distribution on the adiabatic wall surface.

Figure 5 (c) represents the $\eta_{\text {aw }}$ at $M=1.1$, whereby there is an over-prediction at position $\mathrm{x} / \mathrm{H}>4$ which occurred opposite phenomenon at $\mathrm{M}=0.8$, the coolant gas is dominated the temperature distribution on the adiabatic wall surface, since $\eta_{\text {aw }}$ higher generated as compared to $\mathrm{M}=0.5$ and 0.8 .

This reduction is due to the increase in the vortex's discharge coefficient from the coolant ejection slot. It happens within a definite operational range of slot ejection, attributing to an escalating mixing phase amongst the mainstream and the coolant.

\section{CONCLUSION}

In conclusion, the numerical approach using DESSA turbulence model has been worked out to identify three critical parameters of the blade TE cooling system of the gas turbine, i.e., heat transfer on the pin-fins surface $\left(h_{\text {pin }}\right)$, discharge coefficient $\left(C_{D}\right)$, and effectiveness of adiabatic film cooling $\left(\eta_{\text {aw }}\right)$. Both $\eta_{\text {aw }}$ and $C_{D}$ agree well with all the different blowing ratios. The discharge coefficient increases with rising blowing ratios. A slight underprediction has been found in the middle of the blowing ratio and over-prediction in high blowing ratios.

\section{ACKNOWLEDGEMENT}

The authors would like to thank the Universitas Muhammadiyah Surakarta for providing laboratory facilities and financial support.

\section{REFERENCES}

[1] J. Han, 'Recent studies in turbine blade cooling', Rotating Machinery, vol. 10, no. 6, pp.443-457, 2004. https://doi.org/10.1080/10236210490503978

[2] P. Martini, A. Schulz, C.F. Whitney, and E. Lutum, 'Experimental and numerical investigation of trailing edge film cooling downstream of a slot with internal rib arrays', Proceedings of the Institution of Mechanical Engineers, Part A: Journal of Power and Energy, vol. 217, pp.393-401, 2003.

https://doi.org/10.1243/095765003322315450

[3] B. Facchini, L. Innocenti, and L. Tarchi, 'Pedestal and endwall contribution in heat transfer in thin wedge', Proceedings of ASME Turbo Expo No. GT-2004-53152, pp.101-111, 2004. https://doi.org/10.1115/GT200453152
[4] Z. Yang and H. Hu, 'An experimental investigation on the trailing edge cooling of turbine blades', Propulsion and Power Research, vol. 1, no. 1, pp.36-47, 2012. https://doi.org/10.1016/j.jppr.2012.10.007

[5] A.L. Brundage and M.W. Plesniak, 'Experimental investigation of airfoil trailing edge heat transfer and aerodynamic losses', Experimental Thermal and Fluid Science, vol. 31, no. 3, pp.249-260, 2007. https://doi.org/10.1016/j.expthermflusci.2006.04.004

[6] M. Axtmann, R. Poser, J. von Wolfersdorf, and M. Bouchez, 'Endwall heat transfer and pressure loss measurements in staggered arrays of adiabatic pin-fins', Applied Thermal Engineering, vol. 103, pp.1048-1056, 2016. https://doi.org/10.1016/j.applthermaleng.2016. $\underline{04.066}$

[7] J. Joo and P. Durbin, 'Simulation of turbine blade trailing edge cooling', Journal of Fluids Engineering, vol. 131, no. 2, pp.021102, 2009. https://doi.org/10.1115/1.3054287

[8] S.A. Lawson, A.A. Thrift, K.A. Thole, and A. Kohli, 'Heat transfer from multiple row arrays of low aspect ratio pin-fins', International Journal of Heat and Mass Transfer, vol. 54, no. 17-18, pp.4099-4109, 2011. https://doi.org/10.1016/j.ijheatmasstransfer.2011.04.001

[9] N. Azwadi and E. Kianpour, 'The effect of blowing ratio on film cooling effectiveness using cylindrical and row trenched cooling holes with alignment angle of 90 degrees', Mathematical Problems in Engineering, pp. 19, 2014. https://doi.org/10.1155/2014/470576

[10] J. Ahn, I.S. Jung, and J.S. Lee, 'Film cooling from two rows of holes with opposite orientation angles: injectant behavior and adiabatic film cooling effectiveness', International Journal of Heat and Fluid Flow, vol. 24, no. 1, pp.91-99, 2003. https://doi.org/10.1016/S0142-727X(02)00200-X

[11] J. Armstrong and D. Winstanley, 'A review of staggered array pin fin heat transfer for turbine cooling applications', Journal of Turbomachinery, vol. 110, pp. 94-103, 1988. https://doi.org/10.1115/1.3262173

[12] M. Axtmann, J. von Wolfersdorf, and G. Meyer, 'Application of the transient heat transfer measurement technique in a low aspect ratio pin fin cooling channel', Journal of Turbomachinery, vol. 137, 2015, https://doi.org/10.1115/1.4031267

[13] D.E. Metzger, R.A. Berry, and J.P. Bronson, 'Developing heat transfer in rectangular ducts with staggered arrays of short pin-fins', Journal of Heat Transfer, vol. 104, no. 4, pp.700-706, 1982. https://doi.org/10.1115/1.3245188

[14] G. Delibra, D. Borello, K. Hanjalic, and F. Rispoli, 'URANS of flow and endwall heat transfer in a pinned passage relevant to gas-turbine blade cooling', International Journal of Heat and Fluid Flow, vol. 30, pp.549-560, 2009.

https://doi.org/10.1016/j.ijheatfluidflow.2009.03.015 
[15] M.K. Chyu, Y.C. Hsing, T.I.-P. Shih, and V. Natarajan, 'Heat transfer contributions of pins and endwall in pin-fin arrays: Effects of thermal boundary condition modelling', Journal of Turbomachinery, vol. 121, no. 2, pp.257-263, 1999. https://doi.org/10.1115/1.2841309

[16] M. Effendy, Y.F. Yao, and J. Yao, 'Effect of mesh topologies on wall heat transfer and pressure loss prediction of a blade coolant passage', Applied Mechanics and Materials, vol. 315, pp. 216-220, 2013. https://doi.org/10.4028/www.scientific.net/AMM.31 5.216

[17] Y. Yao, M. Effendy, and J. Yao, 'Evaluation of wall heat transfer in blade trailing-edge cooling passage', Applied Mechanics and Materials, vol. 284, pp.738-742, 2013. https://doi.org/10.4028/www.scientific.net/AMM.28 4-287.738

[18] M. Effendy, Y.F. Yao, and J. Yao, 'Comparison study of turbine blade with trailing-edge cutback coolant ejection designs', 51st AIAA Aerospace Sciences Meeting including the New Horizons Forum and Aerospace Exposition, 2013. https://doi.org/10.2514/6.2013-548

[19] M. Effendy, Y.F. Yao, J. Yao, and D.R. Marchant, 'Predicting film cooling performance of trailing-edge cutback turbine blades by detached eddy simulation', 52nd Aerospace Sciences Meeting, 2014. https://doi.org/10.2514/6.2014-0279.

[20] P. Martini, A. Schulz, and S. Wittig, 'Experimental and numerical investigation of trailing edge film cooling by circular coolant wall jets ejected from a slot with internal rib arrays', Turbomachinery, vol. 126, no. 2, pp.229-236,2004. https://doi.org/10.1115/1.1645531

[21] P. Martini, A. Schulz, and H. Bauer, 'Film Cooling Effectiveness and Heat Transfer on the Trailing-edge Cutback of Gas Turbine Airfoils with Various Internal Cooling', Journal of Turbomachinery, vol. 128, pp.196205, 2006, https://doi.org/10.1115/1.2103094

[22] M. Effendy, Y.F. Yao, and J. Yao, 'Pressure loss and wall heat transfer characteristics in blade trailing-edge cooling passage', Proceedings of the International Symposium on Turbulence, Heat and Mass Transfer, 2012. https://doi.org/10.1615/ICHMT.2012.ProcSev IntSymp'TurbHeatTransfPal.560

[23] T. Horbach, A. Schulz, and H.J. Bauer, 'Trailing edge film cooling of gas turbine airfoils - effects of ejection lip geometry on film cooling effectiveness and heat transfer', Heat Transfer Research, vol. 41, no. 8, 2010. https://doi.org/10.1115/1.4002964

[24] D.S. Holloway and J.H. Leylek, 'Pressure-side bleed film cooling: part IE steady framework for experimental and computational results', Proceedings of ASME Turbo Expo 2002 No. GT-2002-30471, pp. 835-843, 2002.
[25] F. Menter and Y. Egorov, 'The scale-adaptive simulation method for unsteady turbulent flow predictions. Part 1: Theory and model description', Flow, Turbulence and Combustion, vol. 85, no. 1, pp. 113-138, 2010. https://doi.org/10.1007/s10494-0102264-5

[26] M. Effendy, Y.F. Yao, and D. R. Marchant, 'Detachededdy simulation of trailing-edge (TE) cutback turbine blade cooling', MATEC Conferences No. 135, p.00008, 2017. https://doi.org/10.1051/matecconf/201713500 $\underline{008}$

[27] H. Schneider, D. Von Terzi, and H. Bauer, 'Largeeddy simulations of trailing-edge cutback film cooling at low blowing ratio', International Journal of Heat and Fluid Flow, vol. 31, no. 5, pp. 767-775, 2010. https://doi.org/10.1016/j.ijheatfluidflow.2010.06.010

[28] J. Krömer, W. Schröder, M. Meinke, P. Comte, C. Brun, and M. Haberkorn, 'LES of transitional boundary layers and wakes with trailing edge blowing', Numerical Flow Simulation III, vol 82. Springer, Berlin, Heidelberg, 2003. https://doi.org/10.1007/978-3540-45693-3 15

[29] M. Effendy, Y.F. Yao, and D.R. Marchant, 'DES study of blade trailing edge cutback cooling performance with various lip-thicknesses', Applied Thermal Engineering, vol. 99, pp.434-445, 2016. https://doi.org/10.1016/j.applthermaleng.2015.11.103

[30] Y. Gao, X. Yan, J. Li, and K. He, 'Investigations into film cooling and unsteady flow characteristics in a blade trailing-edge cutback region', Mechanical Science and Technology, vol. 32, no. 10, pp. 5015-5029, 2018. https://doi.org/10.1007/s12206-018-0949-3

[31] M. Effendy, Y.F. Yao, J. Yao, and D.R. Marchant, 'Detached eddy simulation of blade trailing-edge cutback cooling performance at various ejection slot angles', International Journal of Heat and Fluid Flow, vol. 80, 108487, 2019, https://doi.org/10.1016/j.ijheatfluidflow.2019.108487

[32] M. Effendy, Y.F. Yao, J. Yao, and D.R. Marchant, 'Pinfin shape and orientation effects on wall heat transfer predictions of gas turbine blade', AIP Conference Proceedings, $\quad$ vol. 2114.2019. https://doi.org/10.1063/1.5112392

[33] M. Effendy, Y.F. Yao, D. Sugati, and T. Tjahjono, 'Numerical study of pin-fin cooling on gas turbine blades', AIP Conference Proceedings, vol. 2114. 2019. https://doi.org/10.1063/1.5112493 